\title{
Polymerization shrinkage evaluation of three packable composite resins using a gas pycnometer
}

\section{Avaliação da contração de polimerização de três resinas compactáveis, medida por picnômetro a gás}

\author{
Ricardo Amore* \\ Clóvis Pagani** \\ Michel Nicolau Youssef*** \\ Camillo Anauate Netto**** \\ Hugo Roberto Lewgoy*****
}

\begin{abstract}
Modern restorative dentistry has been playing an outstanding role lately since composite resins, allied to adhesive systems, have been widely applied on anterior and posterior teeth restorations. The evolution of composite resins has mostly been verified due to the improvement of their aesthetic behavior and the increase in their compressive and abrasive strengths. In spite of these developments, the polymerization shrinkage inherent to the material has been a major deficiency that, so far, has been impossible to avoid. Using a gas pycnometry, this research investigated the polymerization shrinkage of three packable composite resins: Filtek P60 (3M), Prodigy Condensable (Kerr), and SureFil (Dentsply/Caulk), varying the distance from the light source to the surface of the resins $(2 \mathrm{~mm}$ or $10 \mathrm{~mm})$. The pycnometer Accupyc 1330 (Micromeritics, USA) precisely records helium displacement, allowing fast and reliable measurements of the volume of composite resin immediately before and after polymerization, without interference of temperature or humidity. Results were not found to be statistically different for the three tested resins, either for $2 \mathrm{~mm}$ or $10 \mathrm{~mm}$-distance from the light source to the composite surface.
\end{abstract}

DESCRIPTORS: Polymers; Dental cements; Dentin-bonding agents; Composite resins.

\begin{abstract}
RESUMO: A Odontologia Restauradora moderna tem se destacado nos últimos anos e as resinas compostas, aliadas aos sistemas adesivos, têm sido muito empregadas para restaurações de dentes anteriores e posteriores. A evolução das resinas compostas tem sido constatada na melhoria do seu comportamento estético e no aumento da sua resistência à compressão e à abrasão. Apesar dos avanços mencionados, a contração de polimerização, inerente a esse material, continua sendo uma grande deficiência e, por enquanto, impossível de ser evitada. Nesta pesquisa a contração de polimerização de três resinas compostas compactáveis, Filtek P60 (3M), Prodigy Condensável (Kerr) e SureFil (Dentsply/Caulk), variando-se a distância entre a fonte de luz e a superficie das resinas em $2 \mathrm{~mm}$ e $10 \mathrm{~mm}$, foi avaliada pelo método da picnometria a gás. O aparelho picnômetro Accupyc 1330 (Micromeritics, EUA) mede o deslocamento de gás hélio com grande precisão, permitindo medições rápidas e fiéis do volume das resinas compostas antes e após a polimerização, sem interferência da temperatura e da umidade. Os resultados mostraram que não houve diferenças estatisticamente significantes entre as três resinas avaliadas. Independentemente do tipo de resina composta, também não houve diferenças significantes para as distâncias de polimerização de $2 \mathrm{~mm}$ e $10 \mathrm{~mm}$.
\end{abstract}

DESCRITORES: Polímeros; Cimentos dentários; Adesivos dentinários; Resinas compostas.

\section{INTRODUCTION}

Until the early 60's, all aesthetic restorative materials available were limited and yielded unsatisfactory clinical results, which were also the main problems observed for the first composite resins.

Although these materials have improved greatly in respect to their mechanical properties, composite resins still present serious problems regarding polymerization shrinkage. Composite materials are composed of an organic resin matrix of dimethylacrylate (Bowen's composite ${ }^{2}, 1962$ ), added to inorganic filler particles, silane, and photo-initiators. In order to obtain polymerization, several molecules combine resulting into chain formations. The combination of the resin molecules brings them closer, thus reducing the total volume of the

*PhD Student; **Associate Professor - Department of Restorative Dentistry of São José dos Campos, School of Dentistry, State University of São Paulo.

***Associate Professor; *****PhD Student - Department of Restorative Dentistry, School of Dentistry, University of São Paulo. $* * * *$ Adjunct Professor, Department of Dentistry, School of Dentistry, University of Mogi das Cruzes. 
Amore R, Pagani C, Youssef MN, Anauate Netto C, Lewgoy HR. Polymerization shrinkage evaluation of three packable composite resins using a gas pycnometer. Pesqui Odontol Bras 2003;17(3):273-7.

material, a process which is known as polymerization shrinkage.

The total volumetric shrinkage may be observed during two phases: pre-gel and post-gel. Polymerization shrinkage starts immediately after light activation; however during the pre-gel state, composite resins are able to flow, thus reducing the stress generated towards the dental structure ${ }^{6,9}$. At the post-gel state, when the material is no longer capable of flowing due to its high viscosity, it is not possible to compensate for the polymerization stress. This phase is related to an increase on composite hardness and, therefore, reflects on its modulus of elasticity. Thus, the post-gel phase may compromise the restorative procedure and the adhesion of the composite resin to the tooth ${ }^{18}$.

Lately, several research works have recommended a decrease of light intensities during polymerization with the purpose of retarding the conversion process, therefore preventing a quick increase on viscosity of the composite resins. Different studies have suggested a variation of the distance from the light source to the composite resin restoration ${ }^{10,13}$.

Using a gas pycnometer, this research investigated the polymerization shrinkage of three different packable composite resins, varying the distance from the light source to the material surface. Pycnometry has been utilized in dentistry to determine the volume or the density of samples of composite resins as well as other materials that undergo a polymerization process. Previous investigations have evaluated the polymerization shrinkage of composite resins through mercury or water pycnometers or dilatometers, or still by using linometers. Such techniques have demonstrated similar results, but fail in some aspects: the mercury dilatometer may compromise health due to its volatile state ${ }^{15}$, is rather sensitive to thermal changes ${ }^{7}$, and produces opacity after light irradiance, which makes this method inadequate for investigating light activated materials ${ }^{20}$. Water pycnometers and dilatometers are influenced by temperature changes and water sorption of composite resins ${ }^{1}$. Linometer readings present high distortion due to the effects of gravity, the load of the measuring system or the lack of uniformity during the polymerization shrinkage ${ }^{7}$.

\section{MATERIAL AND METHOD}

Three packable composite resins were selected for this investigation: Filtek P60 (3M Dental, St. Paul, MN, USA), Prodigy Condensable (Kerr, Port- land, USA), and SureFil (Dentsply/Caulk, Milford, USA). For Filtek P60 and Prodigy Condensable, hue and saturation "A3" was selected. For SureFil, hue "A" was selected since Dentsply does not provide different color saturations for their composite materials.

The specimens were obtained by using a steel matrix of $16 \mathrm{~mm}$ in diameter and $28 \mathrm{~mm}$ in height. A trapezoidal trail, measuring $6 \mathrm{~mm}$ in width on top, $8 \mathrm{~mm}$ in width on the base and $3 \mathrm{~mm}$ in height, was designed on the central portion of the flat side of the matrix. This trail (female) was necessary to allow a perfect fit to a "male" piece. A cavity of $3 \mathrm{~mm}$ in diameter and $3 \mathrm{~mm}$ in depth was made on the center of the "male" fit to determine standard specimens.

The "male-female" coupling was obtained using two screws disposed symmetrically $2 \mathrm{~mm}$ away from the cavity margins. The screws offered not only fixation but also provided a standard distance from the light-tip to the composite resin's surface during polymerization. Since the distance from the light source to the surface of the material was one of the variables studied, four screws were designed: two of them were $2 \mathrm{~mm}$ in height while the other two were $10 \mathrm{~mm}$ in height.

Polymerization shrinkage was determined using a pycnometer Accupyc 1330 (Micromeritics, Norcross, Georgia, USA), which precisely records helium displacement, allowing fast and reliable measurements of the volume of composite resin immediately before and after polymerization. In order to guarantee reproducibility and fidelity to the results, the gas pycnometer was always working under controlled room temperature of $20 \pm 2^{\circ} \mathrm{C}$.

Composite resins were inserted into the cavity of the steel matrix until it was totally filled. Special care was taken at this time to obtain standard volumes of composite resin on the surface of the cavity. Therefore, the first analysis was important to determine a correct contour, leveling, and accommodation of the composite resin to the matrix margins.

All specimens were then weighed on an electronic digital scale PE 360 Mettler to determine the precise mass of the composite resins inserted into the cavity. Since the volume of composite resin studied was small, differences in composite resin formulations, specially regarding the amount of filler particles, did not interfere with the mass of the specimens. Therefore, a standard value of $47 \mathrm{mg}$ was set for all three composites tested. After 
Amore R, Pagani C, Youssef MN, Anauate Netto C, Lewgoy HR. Polymerization shrinkage evaluation of three packable composite resins using a gas pycnometer. Pesqui Odontol Bras 2003;17(3):273-7.

the cavity was filled, each specimen was placed into the measurement chamber and the total volume of material was registered.

For polymerization, specimens were carefully removed from the measurement chamber and placed on a flat surface. Light activation was conducted using the Ultralux Electronic device (Dabi Atlante, São Paulo, Brazil) under $600 \mathrm{~mW} / \mathrm{cm}^{2}$ (determined using a radiometer Demetron - Demetron Research, USA). The light-tip was placed over the fixation screws of the "male-female" fit to guarantee a standard distance of either $2 \mathrm{~mm}$ or $10 \mathrm{~mm}$ from the light source to the surface of the composite resin, according to the tested group. Light activation was carried out during 20 seconds for Filtek P60 and Prodigy Condensable while SureFil required 40-second activation, according to the manufacturers' instructions.

After polymerization, specimens were submitted to a second volumetric analysis in the measurement chamber. The volumetric difference between the values obtained before and after polymerization was calculated and named $\Delta \mathrm{V}$ (delta V).

A third measurement was carried out for each specimen after they were removed from the metallic matrix. The matrix was totally disassembled and the composite resin volume itself (referred to as v) was registered following the same protocol described previously.

Thirty repetitions were obtained for each tested group and polymerization shrinkage was determined using the equation of volumetric contraction: $C=\Delta V / v+|\Delta V|$.

The data obtained were submitted to statistical analysis in order to verify statistical differences between the groups. Therefore, ANOVA and $t$-test were performed.

\section{RESULTS}

Mean polymerization shrinkage values (percentage) of the six tested groups are shown on Table 1 .

The $\mathrm{p}$-value for polymerization shrinkage of the three tested composite resins was 0.4631 ( $p>0.05)$, evidencing that the results obtained were not found to be statistically different. Regarding the evaluated distances $(2 \mathrm{~mm}$ or $10 \mathrm{~mm})$, no statistically different values were observed among the tested resins.

The $t$-test was applied to determine the effect of the distance from the light-tip to the surface of the
TABLE 1 - Mean percentage values of polymerization shrinkage for the evaluated materials.

\begin{tabular}{r|c|c|c}
\hline \hline & Filtek P60 & Prodigy & SureFil \\
\hline $2 \mathrm{~mm}$ & -1.84 & -1.69 & -1.98 \\
\hline $10 \mathrm{~mm}$ & -1.62 & -1.14 & -1.45 \\
\hline \hline
\end{tabular}

material within the same composite. Since there were only two measurements to be compared, each group representing a composite resin was isolated from the others and the $t$-test was performed.

Filtek P60 $(p=0.65)$, Prodigy $(p=0.1398)$ and SureFil $(\mathrm{p}=0.1175)$ presented $\mathrm{p}$-values higher than 0.05 , which indicated that there were no statistical differences between the $2 \mathrm{~mm}$ or $10 \mathrm{~mm}$ protocols.

\section{DISCUSSION}

Composite resins, allied to adhesive systems, have been largely applied on anterior and posterior teeth restorations. Although great improvement has been noticed on composite resins' properties, the polymerization shrinkage inherent to the material is the main concern related to most deficiencies found on aesthetic restorations.

An inorganic filler content, which also interferes during the polymerization shrinkage process, may be found in Filtek P60 as round zircon and silicon particles that are not treated with silane, in proportions of $61 \%$ by volume or $84 \%$ by weight. Condon, Ferracane ${ }^{3}$ (1998) investigated the polymerization shrinkage of composite resins, which filler content was either treated with silane or not, and verified that the inclusion of particles without silane to composite resin formulations may relieve the polymerization stress and reduce volumetric contraction. However, there are no records on the mechanical behavior of such materials in longitudinal evaluations. The main questions arise from the wear resistance and surface roughness of these composites, since the lack of a silane treatment of the inorganic particles might result in loss of adhesion between the filler content and the organic matrix.

Prodigy Condensable presents glass particles of barium aluminum borosilicate combined to colloidal silica, in concentration of $80 \%$ by weight, while SureFil is composed of particles of aluminum fluorosilicate and barium glass, correspondent to $82 \%$ by weight.

Davidson, De Gee ${ }^{6}$ (1984) and Versluis et al. ${ }^{19}$ (1998) support that a higher inorganic filler con- 
Amore R, Pagani C, Youssef MN, Anauate Netto C, Lewgoy HR. Polymerization shrinkage evaluation of three packable composite resins using a gas pycnometer. Pesqui Odontol Bras 2003;17(3):273-7.

tent in composites results in a higher modulus of elasticity and lower flowing during the pre-gel state. Condon, Ferracane ${ }^{4}$ (2000) evaluated the magnitude of polymerization and observed that the composite resins of lower filler content presented lower polymerization stress when compared to those composites whose amount of inorganic particles represented values over $75 \%$ by weight. It is important to remind that the higher the volume of inorganic particles, the lower the polymerization shrinkage levels become, until they reach a limit where the material flow gets compromised. From that limit on, an extra amount of diluents is necessary to overcome the high viscosity of the material, which negatively interferes with polymerization shrinkage.

Mean polymerization shrinkage values for Filtek P60, Prodigy Condensable, and SureFil at a $2 \mathrm{~mm}$-distance from the light-tip to the composite material were $1.84 \%, 1.69 \%$, and $1.98 \%$, respectively. Although no statistically different data have been found for the evaluated resins, mean values of polymerization shrinkage may indicate a tendency of behavior.

Indeed, the small differences found on mean data for volumetric contraction are probably the result of either lower or higher modulus of elasticity observed for each material. It is relevant to state that, in spite of the differences found in the formulations of the composite resins tested, no statistically significant results could be noticed.

Based on the results found in this study, we agree with Rueggeberg et al. ${ }^{17}$ (1994) who stated that factors dependant on the manufacturer, such as composition of the organic matrix, type and amount of inorganic particles as well as color saturation of the material, represent a minimal impact on the final polymerization shrinkage when compared to the variables controlled by clinicians, like light intensity, polymerization method, light activation period, and depth of the composite increment.

Variation of the distance from the light-tip to the surface of the composite resin has been proposed as one of the methods for better controlling the light irradiance that reaches the material and regulating the speed of conversion during polymerization, thus minimizing its effects on polymerization shrinkage.

Investigations carried out by Hansen, Assmus$\operatorname{sen}^{8}$ (1997) and Prati et al. ${ }^{14}$ (1999) demonstrated that the light intensity is significantly reduced when varying the distance from the light source to the surface of the composites. The authors considered it a simple and efficient technique to decrease the speed of conversion and reduce polymerization stress. The further the light source is positioned, the slower the polymerization process occurs. However, this may result in incomplete polymerization, lower degree of conversion, lower modulus of elasticity, and reduced values of microhardness in the deeper increments of the restoration.

The light irradiance utilized in this study was determined using a radiometer (Demetron), as $600 \mathrm{~mW} / \mathrm{cm}^{2}$ for the $2 \mathrm{~mm}$ distance. When the distance from the light-tip to the meter increased to $10 \mathrm{~mm}$, light irradiance was reduced to $480 \mathrm{~mW} / \mathrm{cm}^{2}$. The reduction of light intensity to a value that could still be considered efficient for adequate polymerization may be the reason for the absence of statistically different values among the groups. Moseley et al. ${ }^{11}$ (1986) have found a reduction in light irradiance from $30 \%$ to $50 \%$ for distances of $2 \mathrm{~mm}$ and $10 \mathrm{~mm}$, depending on the light source tested.

Murchison, Moore ${ }^{12}$ (1992) and Rueggeberg, Jordan $^{16}$ (1993) have defended that the degree of conversion is mostly related to the light activation period and the raise in temperature rather than to the variation of the distance from the light source to the surface of the composite resin.

In this study, the mean values of polymerization contraction indicate a tendency of higher shrinkage for the composite SureFil, which may be related to the light activation period recommended by the manufacturer (40 seconds), since Filtek P60 and Prodigy Condensable required only 20 seconds of light exposure. In this case, the degree of conversion may have been higher due to the raising in temperature or to higher activation of the photo-initiators.

The only investigation on polymerization shrinkage of composite resins using a gas pycnometer was carried out by Cook et al. ${ }^{5}$ (1999). The authors observed that this method was reliable and reproducible to detect volumetric changes, without the interference of either temperature or humidity.

Mean polymerization shrinkage values obtained in this study at the distance of $2 \mathrm{~mm}$ were similar to the data supplied by the manufacturers, which enhances the fidelity of this method. According to information provided by $3 \mathrm{M}$, Kerr, and Dentsply, composite resins Filtek P60, Prodigy 
Amore R, Pagani C, Youssef MN, Anauate Netto C, Lewgoy HR. Polymerization shrinkage evaluation of three packable composite resins using a gas pycnometer. Pesqui Odontol Bras 2003;17(3):273-7.

Condensable and SureFil shrink, respectively, $1.8 \%, 1.8 \%$ and approximately $2.0 \%$. Data found in this research were: $1.84 \%, 1.69 \%$, and $1.98 \%$ respectively.

Characteristics such as automaticity, fidelity of results, practicality, and lack of interference by either temperature or humidity make gas pycnometry a promising technique for the investigation of volumetric changes of resin-based materials. However, further studies are necessary to investi-

\section{REFERENCES}

1. Bandyopadhyay S. Study of the volumetric setting shrinkage of some dental materials. J Biomed Mater Res 1982; 16:135-44.

2. Bowen RL. Dental filling material comprising vinyl-silane treated fused silica and a binder consisting of the reaction product of bisphenol and glycidyl methacrylate. US P.I. 1962; 3066112 apud Peutzfeldt A. Resin composites in dentistry: the monomer systems. Eur J Oral Sci 1997; 105:97-116.

3. Condon JR, Ferracane JL. Reduction of composite contraction stress through non-bonded microfiller particles. Dent Mater 1998;14:256-60.

4. Condon JR, Ferracane JL. Assessing the effect of composite formulation on polymerization stress. J Am Dent Assoc 2000;131:497-503.

5. Cook WD, Forrest M, Goodwin AA. A simple method for the measurement of polymerization shrinkage in dental composites. Dent Mater 1999;15:447-9.

6. Davidson CL, De Gee AJ. Relation of polymerization contraction by flow in dentinal composite. J Dent Res 1984; 63:146-8.

7. De Gee AF, Feilzer AJ, Davidson CL. True linear polymerization shrinkage of unfilled resins and composites determined with a linometer. Dent Mater 1993;9:11-4.

8. Hansen EK, Asmussen E. Visible-light curing units: correlation between depth of cure and distance between exit window and resin surface. Acta Odontol Scand 1997; 55:162-6.

9. Kato H. Relationship between the velocity of polymerization and adaptation to dentin cavity wall of light-cured composite. Dent Mater 1987;6:32-7. gate its fidelity and reproducibility under different conditions or methodologies tested.

\section{CONCLUSIONS}

According to the aim of this study and based on the data obtained, no statistically different results were observed in the polymerization shrinkage of the three tested composite resins, regardless of the material or the evaluated distances of $2 \mathrm{~mm}$ or $10 \mathrm{~mm}$.

10. Mehl A, Hickel R, Kunzelmann H. Physical properties and gap formation of light-cured composites with and without softstart-polymerization. J Dent 1997;25:321-30.

11. Moseley H, Strang R, Stephen KW. An assessment of visible-light polymerizing sources. J Oral Rehabil 1986; 13:215-24.

12. Murchison DF, Moore BK. Influence of curing time and distance on microhardness of eight light-cured liners. Oper Dent 1992;17:135-41.

13. Pires JAF, Cvitko E, Denehy GE, Swifth Jr EJ. Effects of curing tip distance on light intensity and composite microhardness. Quintessence Int 1993;24:517-21.

14. Prati C, Chersoni S, Montebugnoli L. Effect of air, dentin and resin-based composite thickness on light intensity reduction. Am J Dent 1999;12:231-4.

15. Rees JS, Jacobsen PH. The polymerization shrinkage of composite resins. Dent Mater 1989;5:41-4.

16. Rueggeberg FA, Jordan DM. Effect of light-tip distance on polymerization of resin composite. Int $\mathrm{J}$ Prosthodont 1993;6:364-70.

17. Rueggeberg FA, Caughman WF, Curtis Jr JW. Effect of light intensity and exposure duration on cure of resin composite. Oper Dent1994;19:26-32.

18. Sakaguchi RL, Peters MCRB, Nelson SR, Douglas WH, Poort HW. Effects of polymerization contraction in composite restorations. J Dent 1992;20:178-82.

19. Versluis A, Tantbirojn D, Douglas WH. Do dental composites always shrink toward the light? J Dent Res 1998; 77:1435-45.

20. Watts DC, Cash AJ. Determination of polymerization shrinkage kinetics in visible-light-cured materials: methods development. Dent Mater 1991;7:281-7.

Recebido para publicação em 27/03/02

Enviado para reformulação em 05/11/02

Aceito para publicação em 14/05/03 